\title{
Simulation of a Himalayan cloudburst event
}

\author{
Someshwar Das ${ }^{1, *}$, Raghavendra Ashrit ${ }^{1}$ and M W MoncriefF ${ }^{2}$ \\ ${ }^{1}$ National Center for Medium Range Weather Forecasting, Noida 201 307, India. \\ ${ }^{2}$ National Center for Atmospheric Research, Boulder CO 80301, USA. \\ *e-mail:somesh@ncmrwf.gov.in
}

\begin{abstract}
Intense rainfall often leads to floods and landslides in the Himalayan region even with rainfall amounts that are considered comparatively moderate over the plains; for example, 'cloudbursts', which are devastating convective phenomena producing sudden high-intensity rainfall $(\sim 10 \mathrm{~cm}$ per hour) over a small area. Early prediction and warning of such severe local weather systems is crucial to mitigate societal impact arising from the accompanying flash floods. We examine a cloudburst event in the Himalayan region at Shillagarh village in the early hours of 16 July 2003. The storm lasted for less than half an hour, followed by flash floods that affected hundreds of people. We examine the fidelity of MM5 configured with multiple-nested domains $(81,27,9$ and $3 \mathrm{~km}$ gridresolution) for predicting a cloudburst event with attention to horizontal resolution and the cloud microphysics parameterization. The MM5 model predicts the rainfall amount 24 hours in advance. However, the location of the cloudburst is displaced by tens of kilometers.
\end{abstract}

\section{Introduction}

While numerical weather prediction (NWP) models are reasonably successful for large-scale medium-range weather forecasting, prediction of precipitation remains a challenge. Mesoscale models, forced by the initial and boundary conditions from the global model forecasts, are widely used to obtain regional forecasts at high spatial and temporal resolution. They account for the influence of detailed topography, land cover, vegetation which are either missing or smoothed in global models. Several operational forecasting centres apply mesoscale models for detailed weather forecasts over small geographical regions.

Mesoscale processes are influenced by surface inhomogeneities in elevation, moisture, temperature, snow cover, vegetation, and surface roughness. Mesoscale weather systems can be divided into two general catagories: those forced primarily by instabilities in travelling systems (e.g., squall lines or mesoscale convective complexes) and those forced by surface inhomogeneities (e.g., mountain/valley circulations). Pielke (1984) noted that terrain-induced mesoscale systems are easier to predict because they are forced by geographically fixed features. Paegle et al (1990) suggested that terrain forced circulation is inherently more predictable than the synoptically induced flows, which are sensitive to the data used to initialize the NWP models. However, they also noted that terrain-induced flows are susceptible to inaccurate numerical treatment of physical processes such as turbulent mixing, radiative heating and soil moisture transport, and also steep terrain.

Cyclonic storms, thunderstorms, squall-lines, land/sea breezes have been widely simulated by mesoscale models but the inherent predictability of terrain-induced circulation and precipitation is debatable. Mesoscale predictability in regions of complex terrain may be enhanced due to deterministic interactions between synoptic-scale flows and the underlying terrain (Mann and Kuo 1998). The influence of terrain on water-vapour transport and precipitation has been the focus of numerous studies; however, after decades of

Keywords. Cloudburst; flash floods; mesoscale; tropical rainfall measuring mission. 
(a) Location of Cloudburst

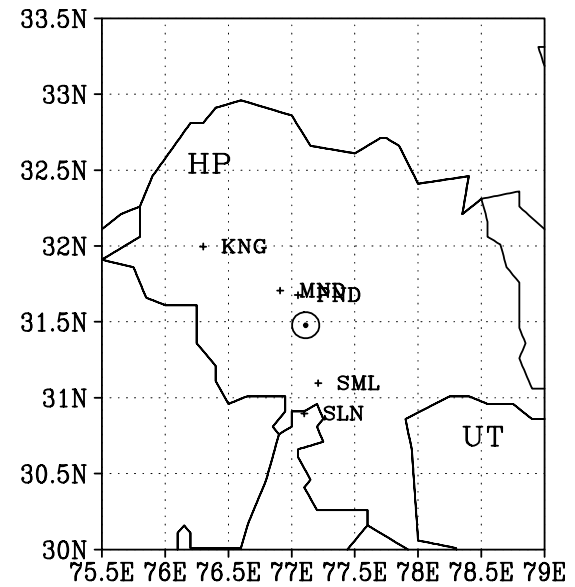

(b) 15Z15JUL2003(UTC) 20:30(IST)

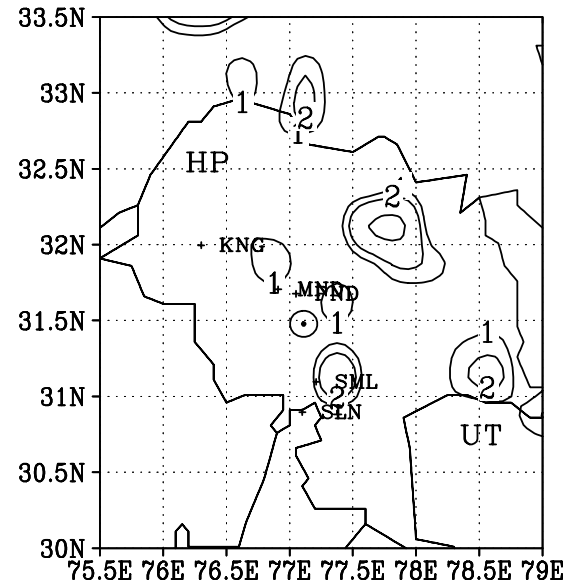

(d) 21Z15JUL2003(UTC) 02:30(IST)

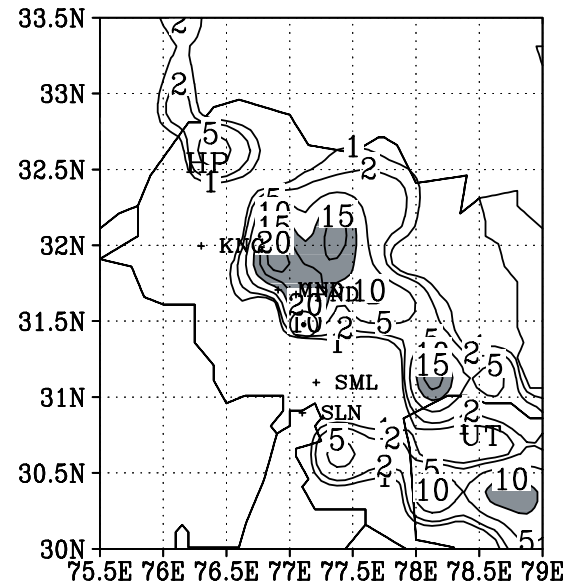

HP Himachal Pradesh

PND Pandoh 9cm

KNG Kangra $5 \mathrm{~cm}$

SLN Solan $2 \mathrm{~cm}$

MND Mandi $2 \mathrm{~cm}$

SML Shimla

$\odot \quad$ Shillagarh

(location of cloudburst)

\section{UT Uttaranchal}

(c) 18Z15JUL2003(UTC) 23:30(IST)

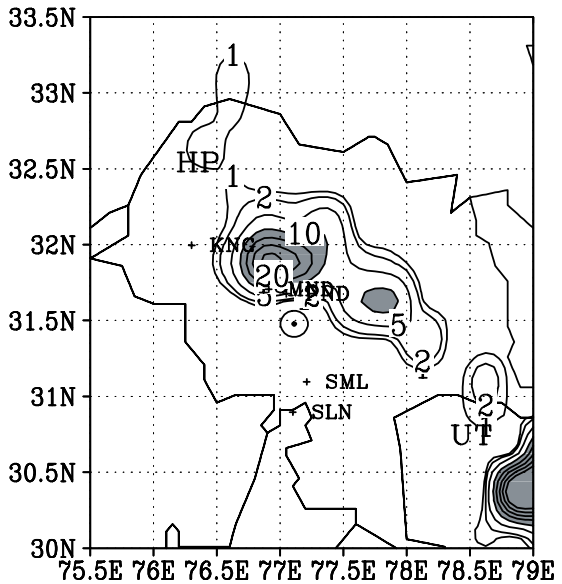

(e) 00Z16JUL2003(UTC) 5:30(IST)

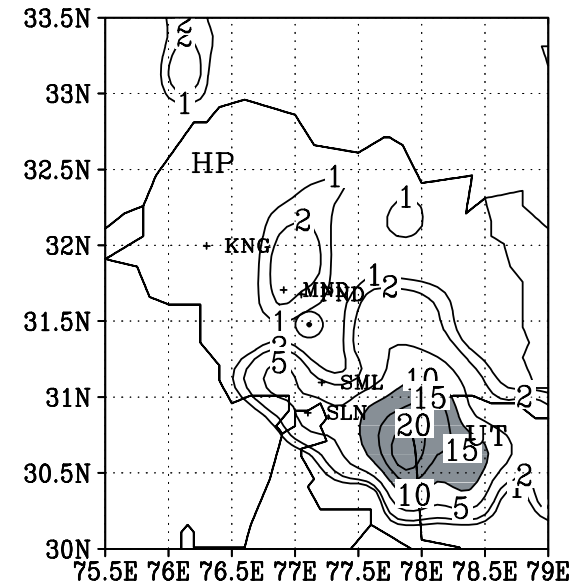

Figure 1. Map showing location of 'cloudburst' marked by a circle and observed (TRMM) rainfall (mm) due to 'cloudburst' event over western Himalayas on 16 July 2003.

effort, the mechanisms of orographic precipitation are still poorly understood and the skillful forecasting of precipitation in mountainous areas remains elusive. Challenges stem from a number of factors, such as interaction between terrain and airflow, latent heating/cooling, and uncertainties in the cloud microphysics. Several orographic mechanisms have been proposed. Smith (1979) described two categories: stratiform precipitation induced/enhanced by stable ascent and convection triggered/enhanced by terrain. Bougeault et al (2001) show that orographic rainfall occurs 
(a) 6JULY2003: 24-hr Rainfall Forecast (mm)

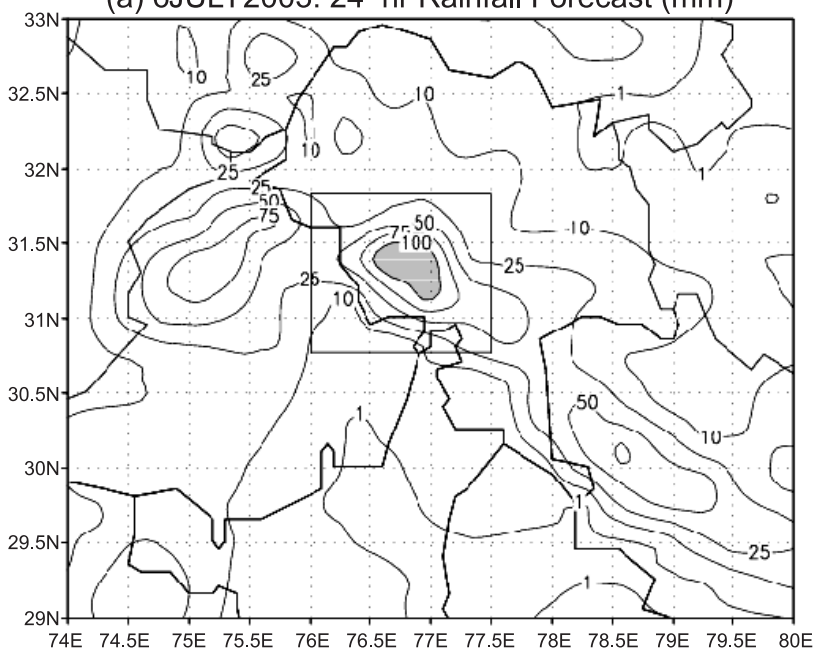

(b) Timeseries of box average rainfall

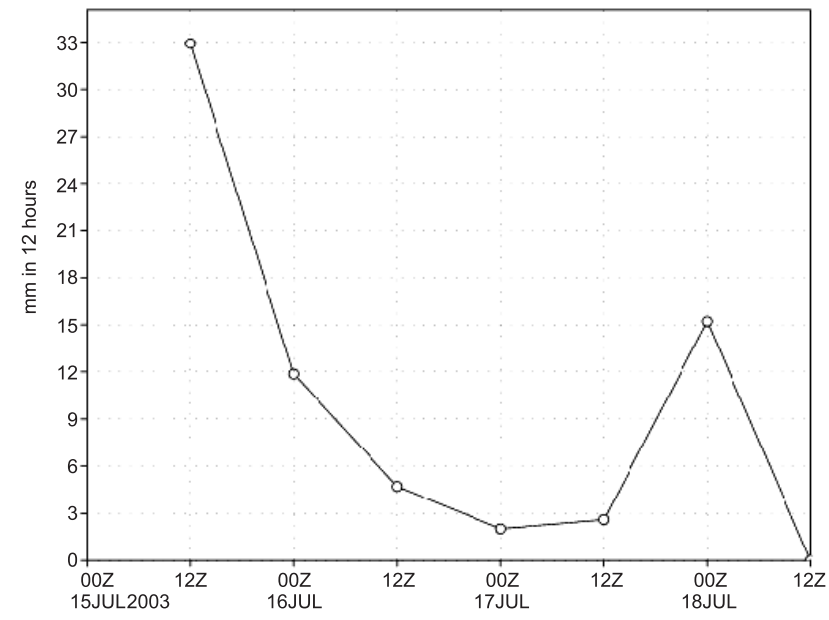

Figure 2. MM5 rainfall ( $\mathrm{mm}$ ) forecast 24 hours in advance. (a) Heavy rainfall due to cloudburst event. (b) Time series of box averaged 12-hour accumulated rainfall.

under a variety of conditions. Chen and Lin (2001) concluded that large amounts of rainfall are produced over the upwind slope in the presence of an impinging low-level jet.

A cloudburst, also known as a rain gush or rain gust is a sudden heavy downpour over a small region, is among the least well-known and understood type of mesoscale system. An unofficial criterion specifies a rate of rainfall equal to or greater than $100 \mathrm{~mm}$ per hour featuring highintensity rainfall over a short period, strong winds and lightning. A remarkably localized phenomenon affecting an area not exceeding $20-30 \mathrm{~km}^{2}$, cloudbursts in India occur when monsoon clouds associated with low-pressure area travel northward from the Bay of Bengal across the Ganges plains onto the Himalayas and 'burst' in heavy downpours (75-100 mm per hour). It represents cumulonimbus convection in conditions of marked moist thermodynamic instability and deep, rapid dynamic lifting by steep orography.

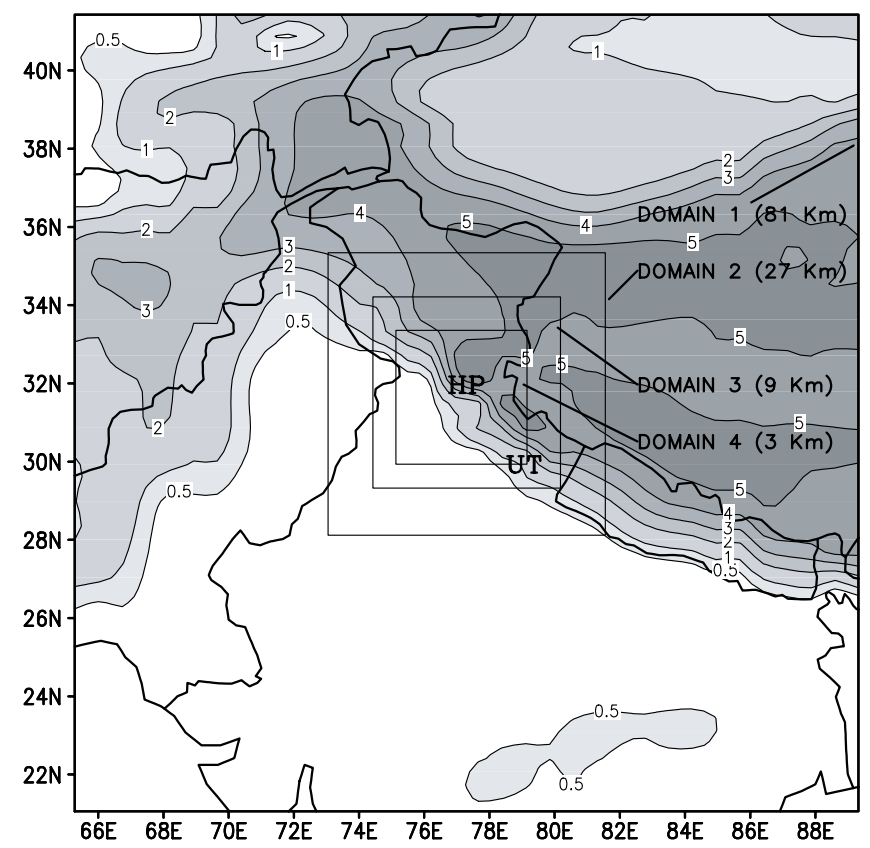

Figure 3. MM5 model nested domains and resolution used for this study. Shading and contours indicate the terrain elevation $(\mathrm{km})$.

Cloudburst events over remote and unpopulated hilly areas often go unreported. The states of Himachal Pradesh and Uttaranchal are the most affected due to the steep topography. Most of the damage to property, communication systems and human causalities result from the flash floods that accompany cloubursts. Prediction of cloudbursts is challenging and requires high-resolution numerical models and mesoscale observations, high-performance computers and Doppler weather radar. Societal impact could be markedly reduced if high-resolution measurement $(\sim 10 \mathrm{~km})$ of atmospheric parameters and vertical profiles are provided through a mesonet observations such as Automatic Weather Station (AWS), Radiosonde/Rawinsonde (RS/RW), and Doppler weather radar. Also, education and training of local administrators to give short-notice warnings would greatly help disaster mitigation.

Cloudburst events occur at the meso-gamma $(2-20 \mathrm{~km})$ scale as defined by Orlanski (1975) and may be difficult to distinguish from thunderstorm. Held (1982) compared radar observations of two similar storms: one, a 1/2 hour-long hailstorm and the other a cloudburst event consisting of two episodes of very heavy rainfall, $174 \mathrm{~mm} / \mathrm{h}$ over $20 \mathrm{~min}$ and $55.2 \mathrm{~mm} / \mathrm{h}$ over 30 minutes. Both storms had similar radar signatures making it difficult to identify the cloudburst. Houze (1993) detailed the dynamics of cloud-producing airflow induced by mountains. Obviously, orographic lifting of moist unstable air releases convective available potential energy (CAPE) necessary for a 

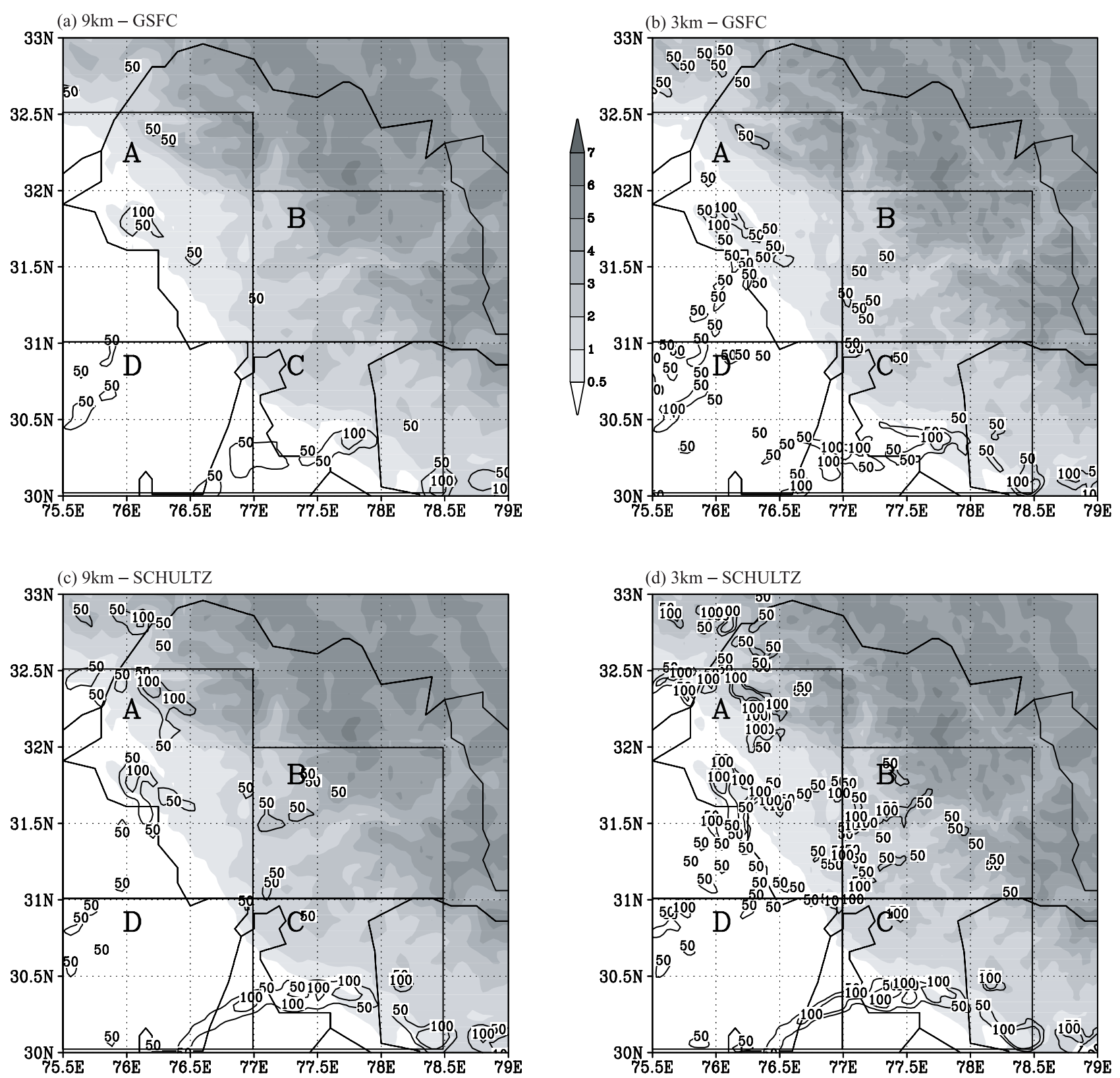

Figure 4. 12-hour forecast of rainfall (mm) valid at 1200 UTC 15 July 2003 at different resolution (a) $9 \mathrm{~km}$ and (b) $3 \mathrm{~km}$ for GSFC moisture scheme. Panels (c) and (d) are same as (a) and (b) respectively for experiment with Schultz scheme. Model terrain elevation at both resolutions are shaded in grey scale. Boxes A, B, C and D indicate regions chosen for spatial averaging. Contour intervals are $50 \mathrm{~mm}$.

cloudburst, but the complex interaction between cloud dynamics and orographic dynamics are only beginning to be addressed. Numerical simulation is useful in this regard.

\section{Approach}

\subsection{Measurements}

The region of interest is a data-sparse region in the western Himalayas where only satellites are available to measure cloudburst events. We use data from the Tropical Rainfall Measuring Mission (TRMM), Microwave Imager (TMI), the Precipitation Radar (PR) which is a 128-element active phased array system operating at $13.8 \mathrm{GHz}$, and Visible and Infrared Radiometer System (VRS). Additionally, TRMM carries the Cloud and Earth's Radiant Energy System (CERES) and the Lightning Imaging System (LIS). TRMM data are available from http://lake.nascom.nasa.gov/data/ dataset/TRMM.

For our purposes, PR is most useful of the three precipitation sensors on TRMM. PR's horizontal resolution is $4.3 \mathrm{~km}$, vertical resolution is 

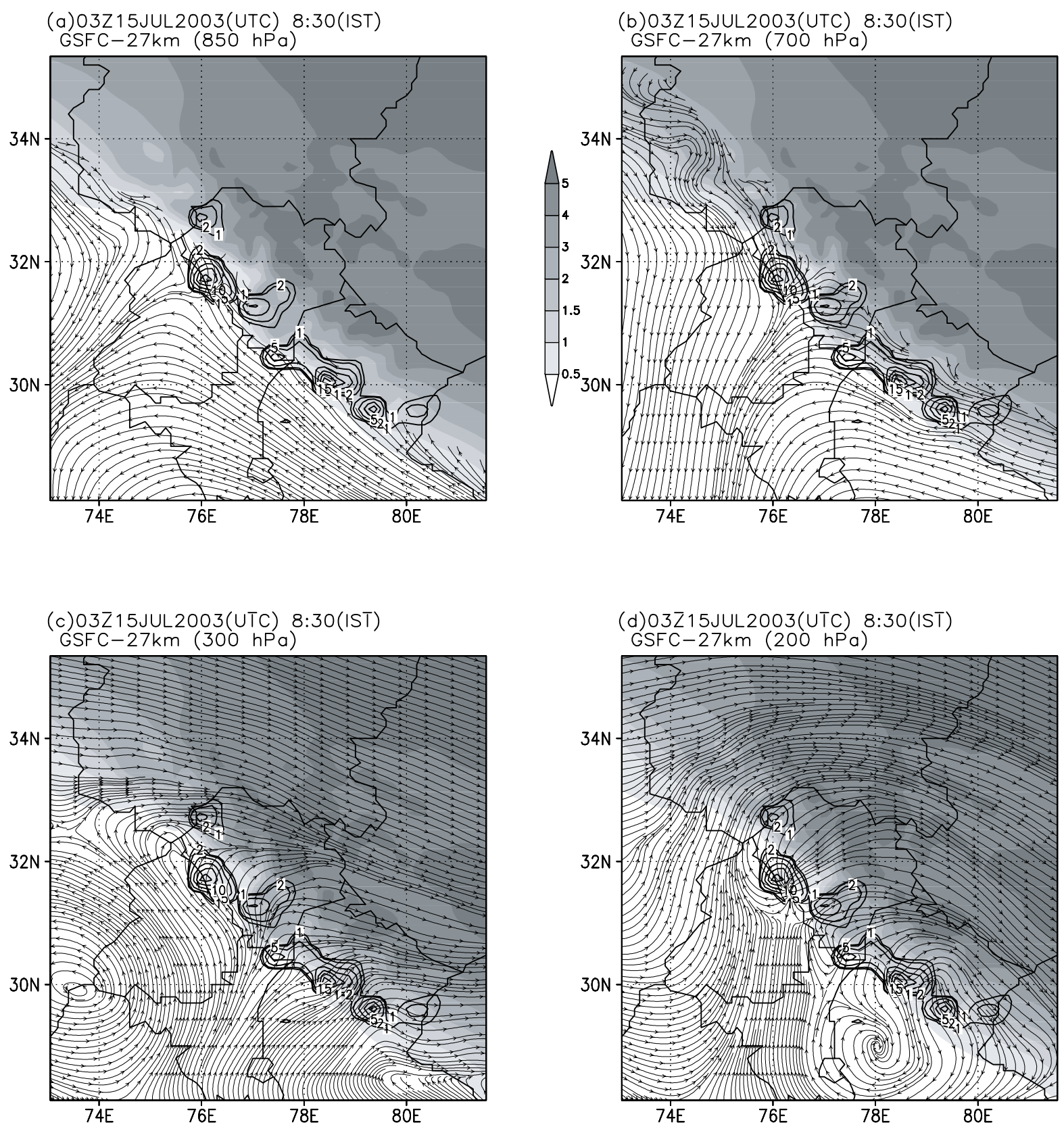

Figure 5. Background large scale flow as seen in domain $2(27 \mathrm{~km})$ on 15 July $2003(08: 30 \mathrm{IST})$ at (a) $850 \mathrm{hPa}$ (b) $700 \mathrm{hPa}$ (c) $300 \mathrm{hPa}$ and (d) $200 \mathrm{hPa}$. Rainfall $(\mathrm{mm})$ in countors and terrain elevation $(\mathrm{km})$ in shading are also shown. The contour intervals of rainfall are $1,2,5,10,15,20 \mathrm{~mm}$.

$250 \mathrm{~m}$, swath width is $215 \mathrm{~km}$, and sensitivity $<0.7 \mathrm{~mm} / \mathrm{h}$ (Kummerow et al 1998). Global estimates are obtained by adjusting the GOES Precipitation Index (GPI) to the TRMM estimates. We use the 2 A12 TMI data and GPI-calibrated rainfall. Rainfall is measured over $0.25 \times 0.25$ degree grid boxes at 3-hour temporal resolution. The $2 \mathrm{~A} 12$ dataset includes cloud liquid water, precipitable water, cloud ice, precipitation ice profiles in 14 layers at $5 \mathrm{~km}$ horizontal resolution, along with latent heat and surface rain, over a $760 \mathrm{~km}$ swath. The combined instrument rain calibration algorithm
(3B42) uses combined rain structure (2B31) and VIRS calibration (1B01) to adjust IR estimates from geostationary observations.

\subsection{The cloudburst event}

The cloudburst event occurred on 16 July 2003 at Shillagarh village in Himachal Pradesh at the foothills of the western Himalayas, about $50 \mathrm{~km}$ from Shimla $\left(31.06^{\circ} \mathrm{N}, 77.13^{\circ} \mathrm{E}\right)$ and $35 \mathrm{~km}$ from Mandi $\left(31.43^{\circ} \mathrm{N}, 76.58^{\circ} \mathrm{E}\right)$. The location of the Shillagarh village is shown in figure 1(a). Occuring 
(a) DOMAIN4: Rainfall Box-A
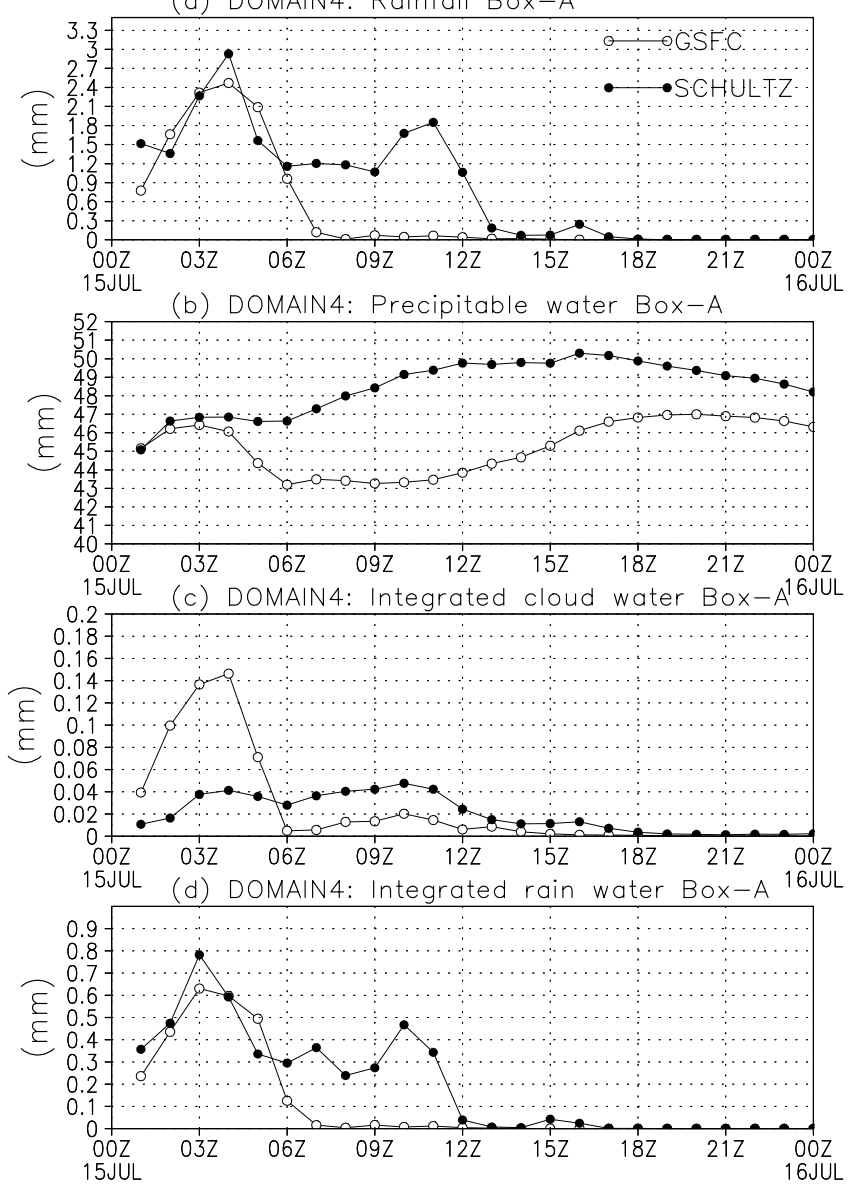

Figure 6. Time series of average (box A) (a) rainfall, (b) precipitable water, (c) integrated cloud water and (d) integrated rain water for experiments with both moisture schemes.

between 0300 and 0400 hours local time, the accompanying flash floods and landslides left 35 dead and 50 injured, disrupted communication systems and power supplies, washed away roads and extensively damaged property. Examples of high 24-hour rainfall in the Himachal Pradesh region from the India Meteorological Department (IMD) are: $9 \mathrm{~cm}$ in Pandoh, $5 \mathrm{~cm}$ in Kangra, $3 \mathrm{~cm}$ in Rajgarh and $2 \mathrm{~cm}$ at Mandi and Solan. The neighbouring Uttaranchal region also reported very heavy rainfall $(8 \mathrm{~cm}$ at Haripur, $7 \mathrm{~cm}$ at Srinagar, $4 \mathrm{~cm}$ at Dehradun and North Tehri).

Figure 1 shows the observed rainfall over the region of Himachal Pradesh (HP) between 1500 UTC (20:30 local time, IST) on 15 July and 0000 UTC (05:30 IST) on 16 July 2003. Two isolated events of heavy precipitation occurred, one over the central part of the State of Himachal Pradesh which was observed at 1800 UTC (23:30 IST) and 2100 UTC (02:30 IST on 15 July) and the other over parts of the neighbouring state of Uttaranchal (UT) at 0000 UTC (05:30 IST) on 16 July. The $0.25^{\circ}$ horizontal resolution of TRMM
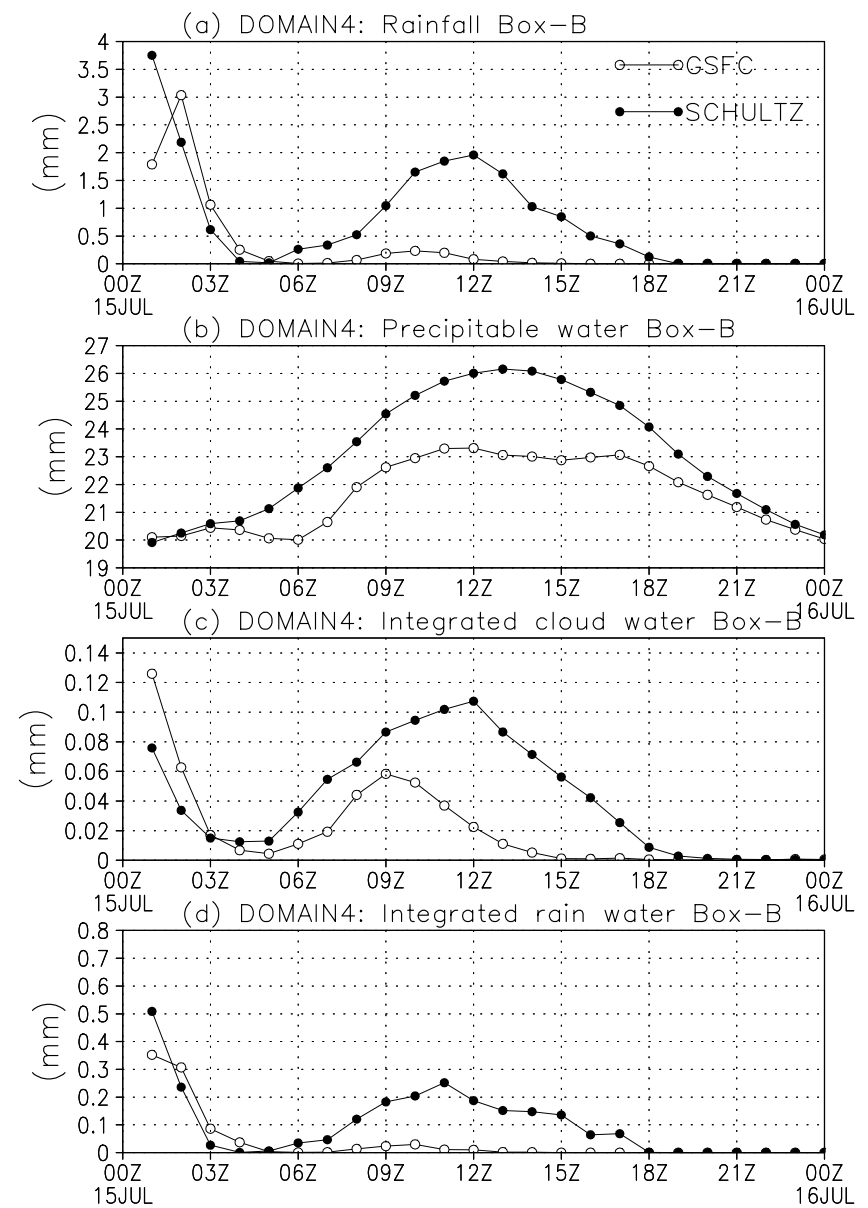

Figure 7. As in figure 6 but for box B.

precipitation measurements means that the rainfall amounts in figure 1 are underestimated compared to the rain-gauge measurements, which exceeded $50 \mathrm{~mm}$. Over hilly areas rainfall amounts in excess of $50 \mathrm{~mm}$ over a short period of time is likely to cause severe flooding and landslides.

\subsection{Configuration of MM5}

The MM5 mesoscale model (version 3.6) is used operationally at NCMRWF for 72-hour forecasts over India at 90,30 and $10 \mathrm{~km}$ grid resolution. MM5 has fruitfully predicted rainfall and atmospheric motion during the summer monsoon, tropical cyclones, west-coast disturbances, thunderstorms and squall lines. The MM5 has also been used at cloud-system-resolving scale simulations over small areas (Das 2002 and http://www.ncmrwf.gov.in/mm5-new-webdes.htm).

The operational 24-hour rainfall forecast from MM5 valid for 16th July 2003 is shown in figure 2(a). A small region over the southern part of Himachal Pradesh (HP) shows the rainfall amount exceeding $100 \mathrm{~mm}$ in 24 hours (box). The 
(a) DOMAIN4: Rainfall Box-C
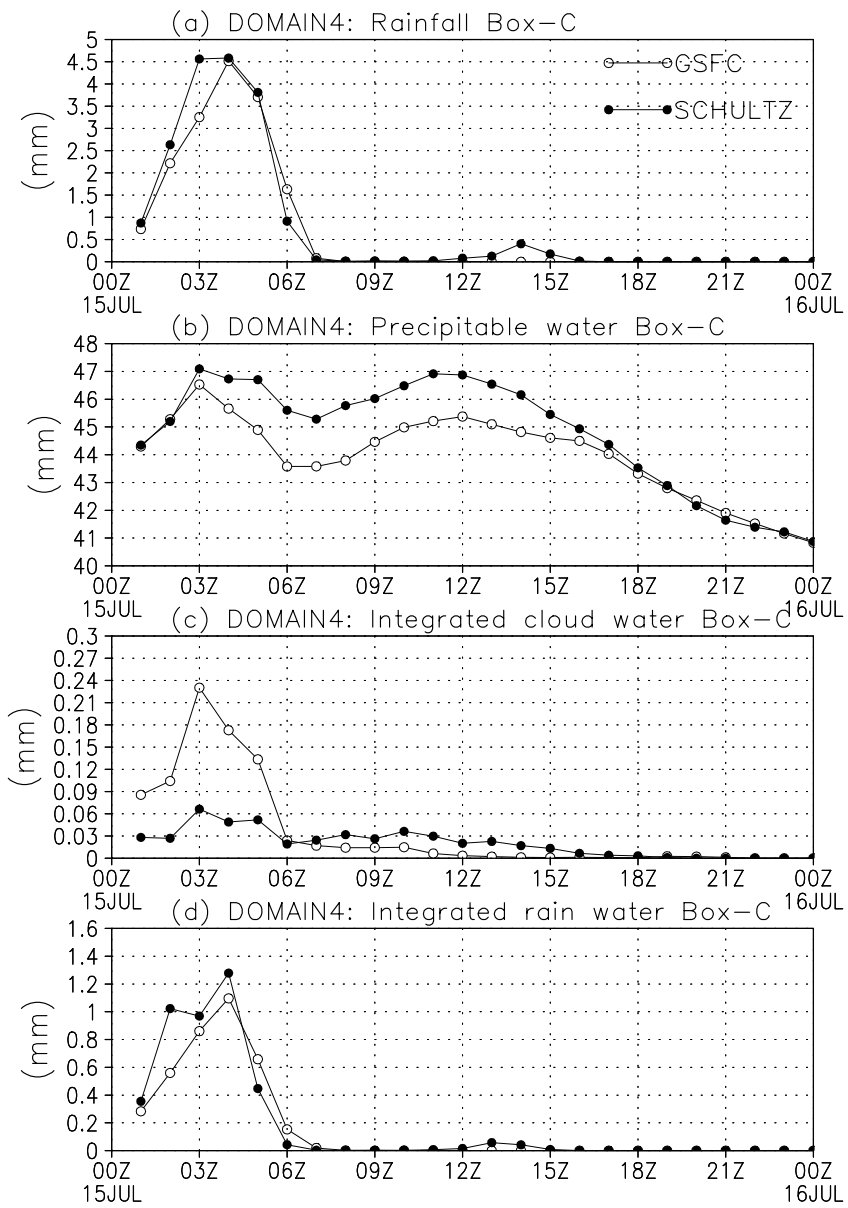

Figure 8. As in figure 6 but for box C.

time series of 12-hour accumulated box-averaged rainfall is shown in figure 2(b). The time series indicates the high rainfall amount in the first 12 hours (i.e., 1200 UTC 17:30 IST) on 15 July 2003, which accounts for most of the 24-hour rainfall. The $30 \mathrm{~km}$ grid-resolution simulation of rainfall is higher than the TRMM observed rainfall (figure 1), but compares closely with the observed rainfall amount reported by IMD (discussed in section $2 \mathrm{~b}$ ). The location of the rainfall maximum in observation and simulation however does not match exactly. The operational T80 analysis valid for 0000 UTC and 1200 UTC 15 July 2003 were used for initial and boundary forcings. Figure 3 shows the four nested domains centered on $31.8^{\circ} \mathrm{N}, 77.3^{\circ} \mathrm{E}$ with horizontal gridresolutions of $81,27,9$ and $3 \mathrm{~km}$ and time steps 180, 60, 20 and 6.67 seconds, respectively. The elevation of the region of interest ranges from $0.5 \mathrm{~km}$ to $5 \mathrm{~km}$ in the Himachal Pradesh. The highresolution domains ( 3 and 4 ) have elevations up to $6.5 \mathrm{~km}$.

MM5 uses the United States Geological Survey (USGS) elevation data (interpolated depending on resolution) with 25 categories for vegetation/land
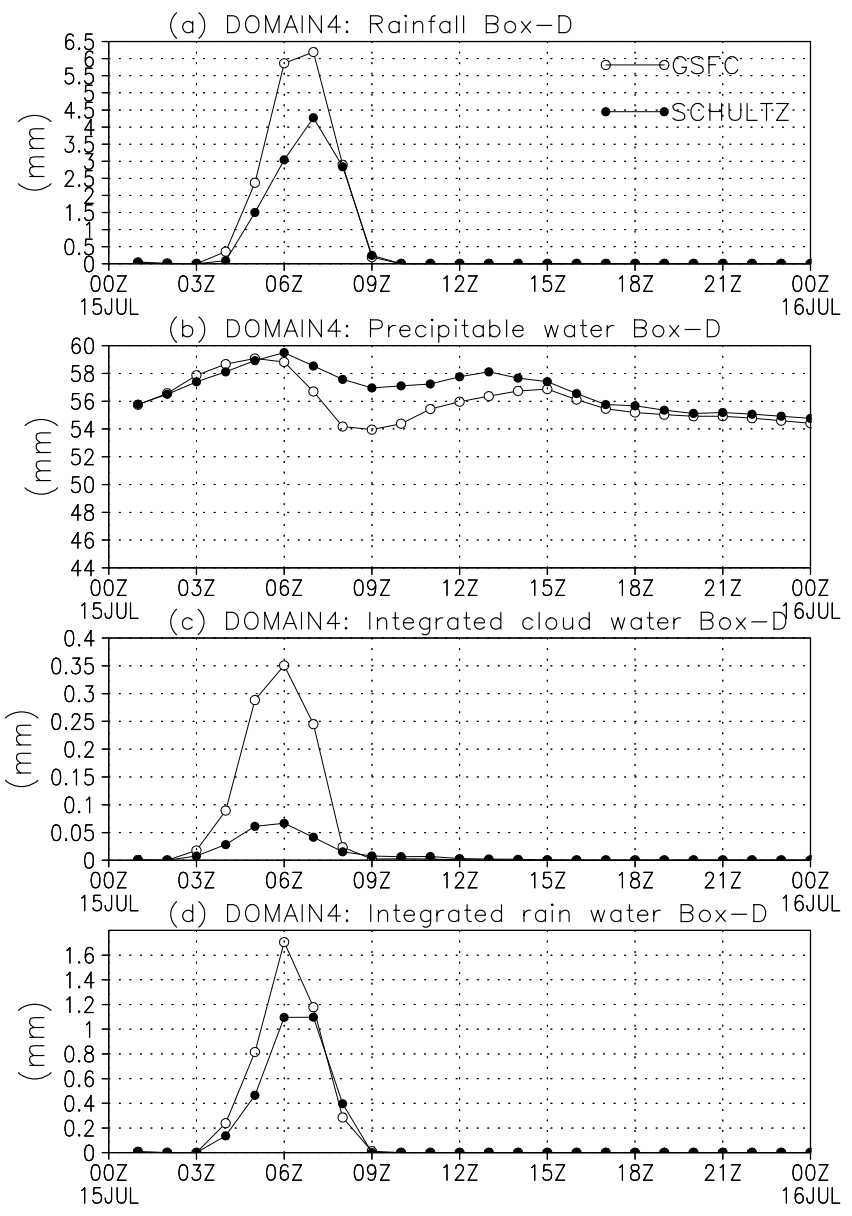

Figure 9. As in figure 6 but for box D.

use and 40 levels in the vertical. We used the Grell (1993) convective parameterization (a simplified Arakawa-Schubert) option and the non-local closure of Hong and Pan (1996) for boundary layer parameterization. The convective parameterization is switched off in domain 4.

Explicit treatment of cloud water, rain water and ice follows Dudhia (1996) in the operational run. Cloud radiation interaction occurs for explicit cloud and clear air. The initial and lateral boundary conditions are obtained from operational global T80 model of NCMRWF. Two experiments are carried out using two schemes of explicit treatment of moisture in the model - GSFC based on Tao et al (1989, 1993) and SCHULTZ based on Schultz (1995). The GSFC scheme is based on NASA/Goddard Space Flight Centre (GSFC) cloud microphysics scheme. It has prognostic equations for two categories of liquid water (cloud water and rain) and three categories of ice (cloud ice, snow, and hail/graupel) based on Lin et al (1983) and Rutledge and Hobbs (1984). The Schultz scheme predicts cloud water, rain water, pristine ice crystals, snow and graupel (sleet or hail), but aggregation of snow crystals is not included. Its 
(a) Rainfall $(\mathrm{mm} / \mathrm{h})$ GSFC
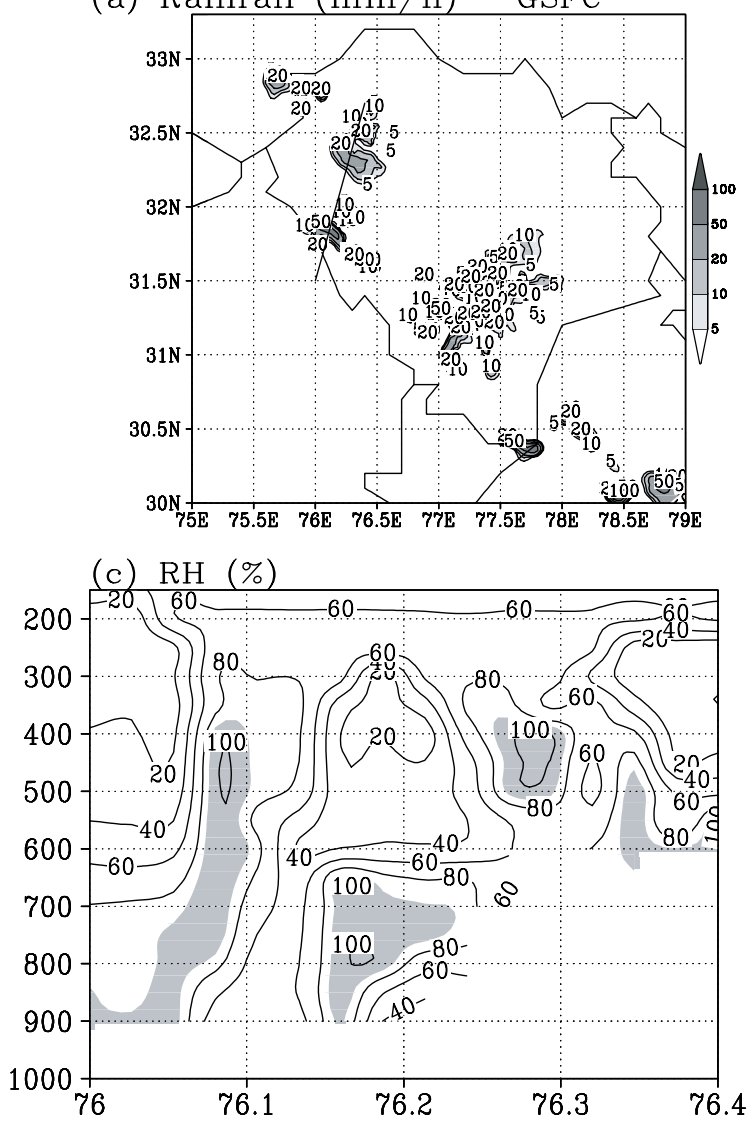

(b) Windspeed $(\mathrm{m} / \mathrm{s})$

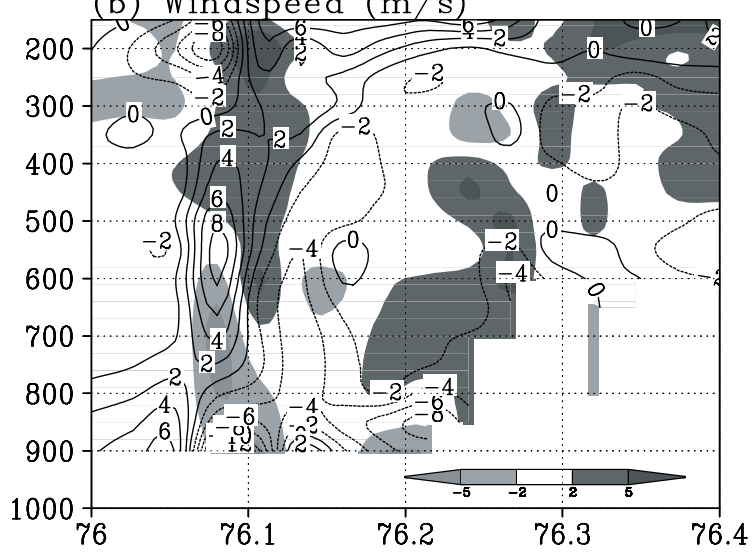

(d) $\omega(\mathrm{Pa} / \mathrm{s})$

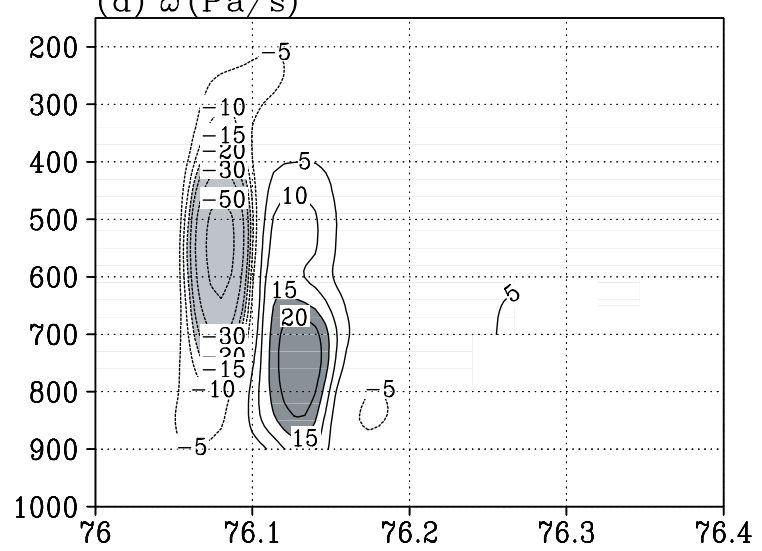

Figure 10. Simulated values by GSFC moisture scheme showing (a) rainfall rate, (b) vertical cross-section of zonal (shaded) and meridional (contours) wind, (c) humidity and (d) vertical velocity over regions of intense rainfall activity on July 15 th 2003 at 7:30 IST. The contour intervals for rainfall are at 5, 10, 20, $50 \mathrm{~mm}$.

merit is computational efficiency for NWP applications and four-dimensional data assimilation, because it has few parameters and a minimal number of floating point operations.

\section{Simulation results}

\subsection{Precipitation}

Detailed hourly analysis shows that the domains 3 and 4 (i.e., $9 \mathrm{~km}$ and $3 \mathrm{~km}$ grid-resolution, respectively) produce 12-hour rainfall amounts as high as $100 \mathrm{~mm}$. Rainfall in the coarse resolution domains were comparatively low. We present detailed results only for domains 3 and 4 . Figure 4 shows the accumulated rainfall (in 12 hours) simulated in the two experiments. The resolved terrain height is shaded and rainfall amounts are shown in contours. Precipitation over the 24-hour period (not shown) was not much different, indicating that most of the rainfall occurred in the first 12 hours. The increased horizontal and vertical resolution could have led to rapid growth and development of convective activity compared to the observation. It would be too much to expect that the model simulations would capture the cloudburst event with high precision in space and time.

In figure 5 streamlines at four levels for domain 2 (27 km grid-resolution) show strong mass convergence along the mountains. Away from the mountains towards the southwest the flow is northeasterly. The upper-level and lower-level directions are opposite indicating strong shear in the intermediate levels. Along the foothills in the regions of intense rainfall activity, the upper-air divergence suggests strong orographic uplift and convection.

Unlike figure 2, the high-resolution domains of 9 and $3 \mathrm{~km}$ shown in figure 4 feature locations of intense rainfall of over $100 \mathrm{~mm}$ in 12 hours. Animated hourly sequences of rainfall (not shown) indicate that bands of rainfall bands (both GSFC and Schultz) originated along the foothills of the Himilayas then traveled southward/southwestward away from the foothills. The area-averaged time series of rainfall, precipitable water, integrated cloud water and integrated rain water computed for the four boxes (A, B, C and D) are shown in figures 6-9 for domain 4 . The time series for box A (figure 6) shows the effects of the two microphysical 
(a)Rainfall $(\mathrm{mm} / \mathrm{h})$ SCHULTZ
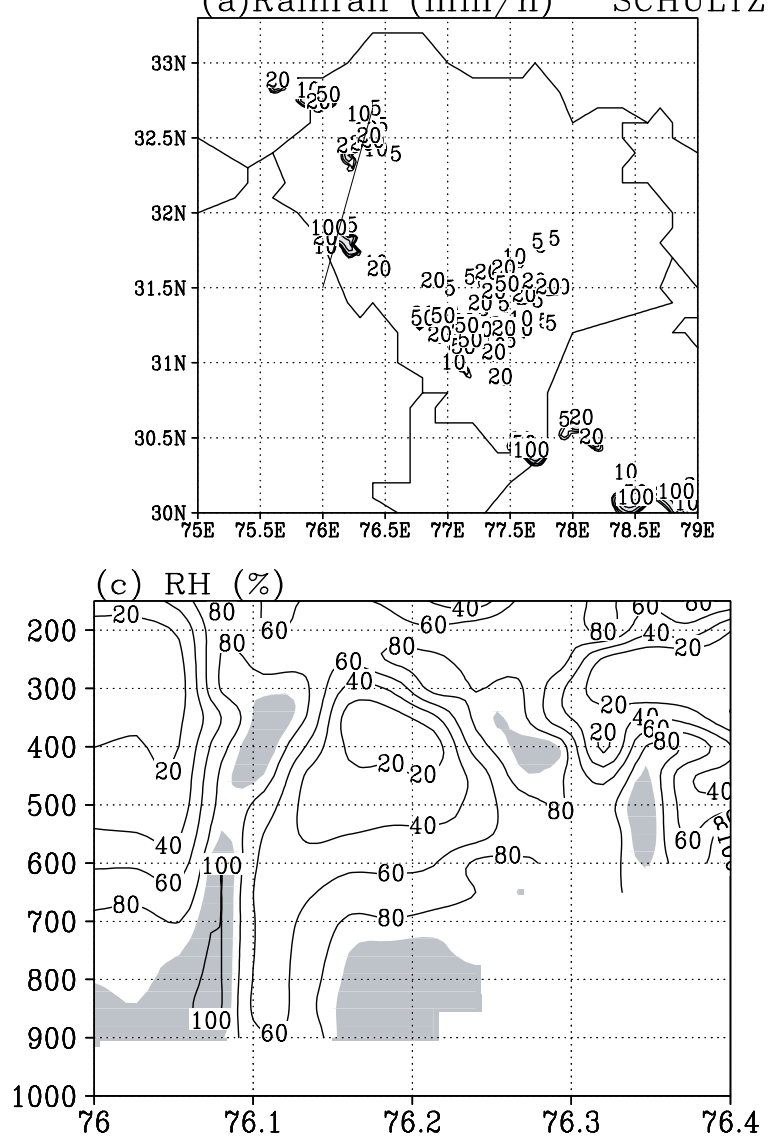

(b) Windspeed $(\mathrm{m} / \mathrm{s})$

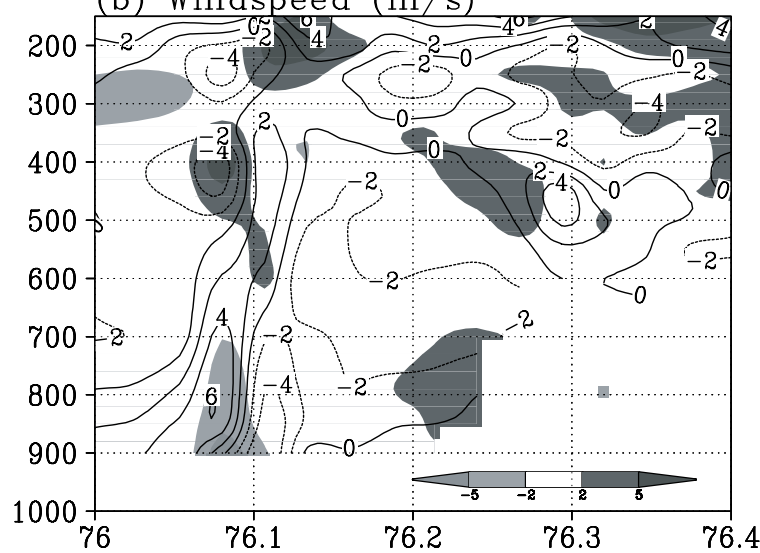

(d) $\omega(\mathrm{Pa} / \mathrm{s})$

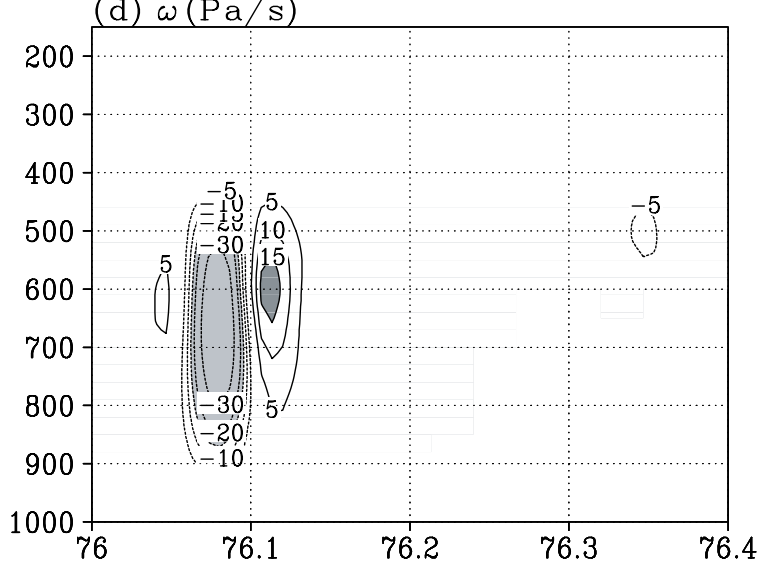

Figure 11. As in figure 10 but for Schultz moisture scheme.

parameterizations. Both have a similar evolution of the rainfall although Schultz produces higher precipitable water. The integrated cloud water is much lower in Schultz than in GSFC.

Figure 7 for box B shows that the magnitudes of all the above four quantities are much lower than in figure 6 . The rainfall peak occurs at 12 UTC and all the parameters show higher magnitudes for the Schultz parameterization. For box C (figure 8) and box $\mathrm{D}$ the evolution is similar to box A; namely, Schultz shows higher precipitable water and lower integrated cloud water. For box D (figure 9), the comparison between the two schemes again suggests similarity. The peaks are displaced by about 3-4 hours because the precipitating systems travel from boxes $\mathrm{A}$ and $\mathrm{C}$ into box D. The two schemes of cloud microphysics predict the moisture variables based on different assumptions. The difference in the results simulated by the two cloud microphysics schemes may be attributed to the difference in the treatment of moisture variables in the two schemes as described in section 2. It is not straightforward to pin-point the cause of the difference, because that requires a number of sensitivity experiments related to the cloud microphysical parameters of the two schemes.
The above time-series analysis suggests that low-level convergence along the foothills and the intense orographic lifting leads to local storms that travel southwestwards steered by the shear flow. The vertical profiles of wind and humidity are now examined to gain further insight into the evolution and travel characteristics of the cloudburst event.

\subsection{Tropospheric circulation}

Cross-section analysis of a mesoscale system identifies key features such as vertical development, shear, time of passage, etc. Environmental vertical motion determines the rate of CAPE realization. Vertical shear of the horizontal wind affects the mesoscale organization, evolution and travel speed of convective storms as well as entrainment rate and precipitation efficiency.

Figure 10(a) shows the location of heavy rainfall at 07:30 IST and vertical cross-section of zonal (shaded) and meridional winds (contours) in figure 10(b), relative humidity (figure 10c) and vertical velocity (figure 10d) for GSFC. The location of the cross-section is indicated in figure 10(a). Similar analysis is performed for Schultz (figure 11). The focal region feaures a rainfall rate as high as 
(a) Rainfall $(\mathrm{mm} / \mathrm{h}) \quad(00: 27 \mathrm{IST})$
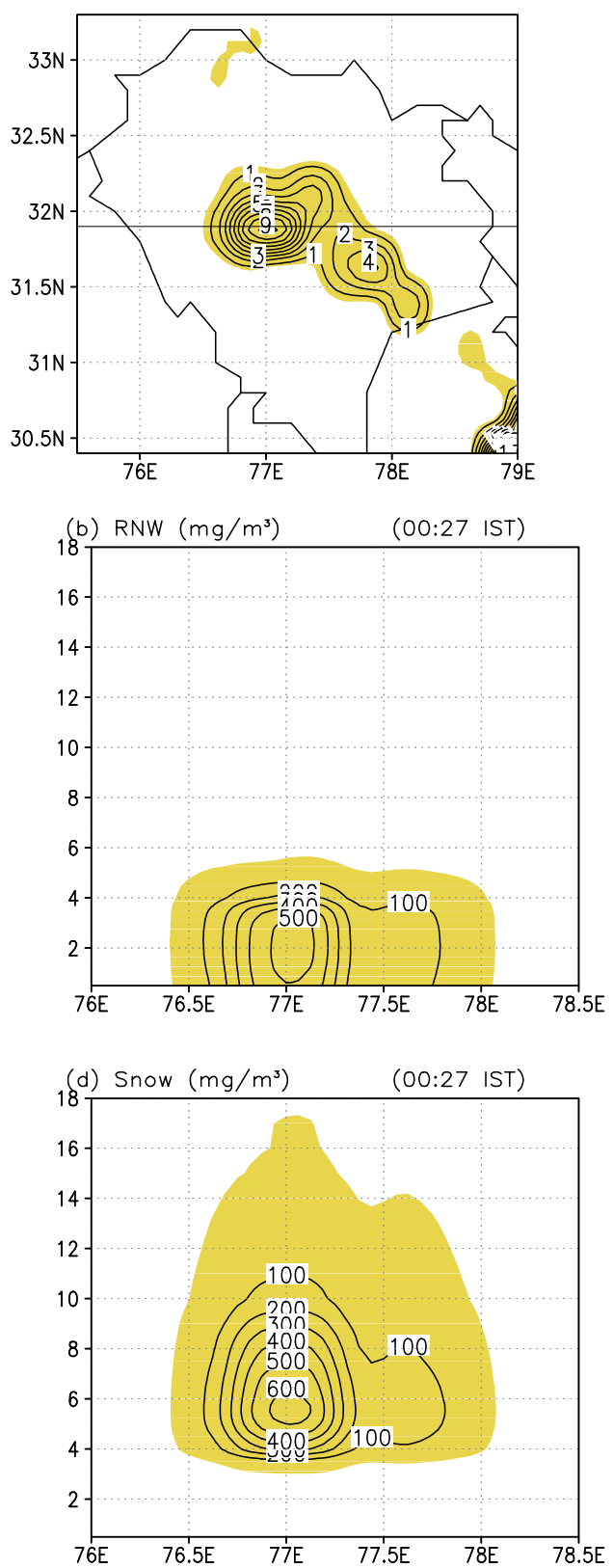

\section{TRMM}
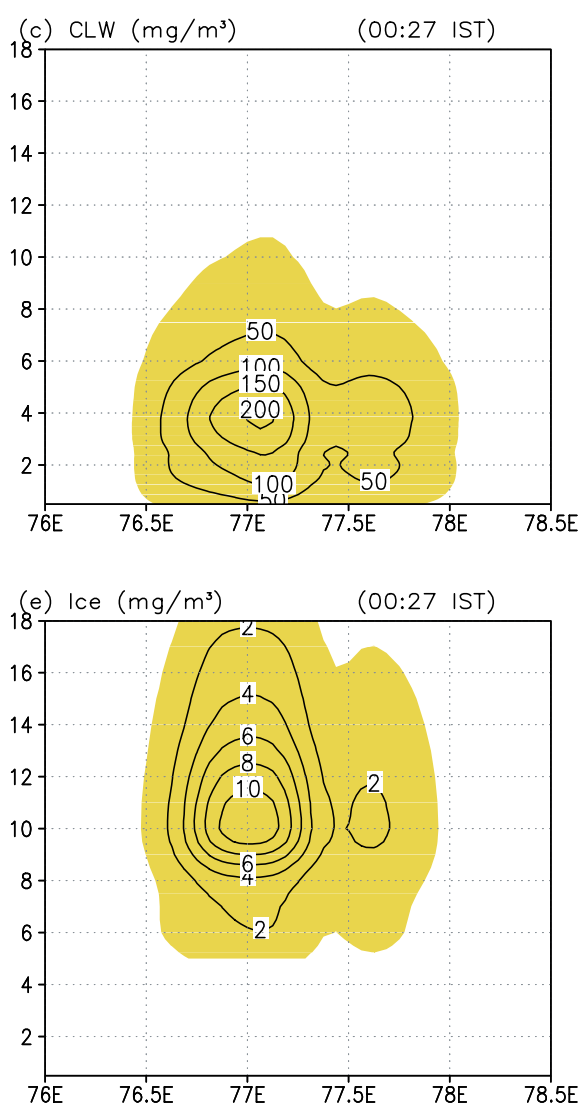

Figure 12. Observed (TRMM) location of (a) intense rainfall and vertical cross-section of hydrometeors, (b) RNW, (c) CLW, (d) snow and (e) ice on 16th July 2003 (00:27 IST).

$50 \mathrm{~mm} / \mathrm{h}$. Figure 10(b) shows the cross-section of windspeed at different levels. The Himalayan orography up to $600 \mathrm{hPa}$ is clearly seen east of $76.2^{\circ} \mathrm{E}$. Contours in figure 10(b) suggest a deep layer of northerlies between $76^{\circ} \mathrm{E}$ and about $76.05^{\circ} \mathrm{E}$ and strong southerlies to the east. Around $76.1^{\circ} \mathrm{E}$ the shadings in figure 10(b) indicate easterlies from near surface up to $600 \mathrm{hPa}$ with westerlies aloft. Westerlies also dominate along the foothills (dark shading) from the surface up to about $500 \mathrm{hPa}$ (around $76^{\circ} \mathrm{E}$ ). The meridional wind component shows intensified vertical shear with a deep layer of strong southerlies from surface up to $300 \mathrm{hPa}$.
Northerlies over the mountains (although weak) and the plains undercut the southerlies, forming a frontal system. The relative humidity shows values in excess of $95 \%$ near the surface over the mountains and the plains. Ascending/desending motion at various levels is shown by the vertical $p$-velocity $\omega$. The impact of vertical shear in the meridional winds and orography affect the triggering of cells of ascending and desending motion. Further downstream at $76.1^{\circ} \mathrm{E}$ convergence and strong shear is clearly evident. The cross-section of vertical velocity indicates enhanced convection attendant to low-level convergence and strong vertical 


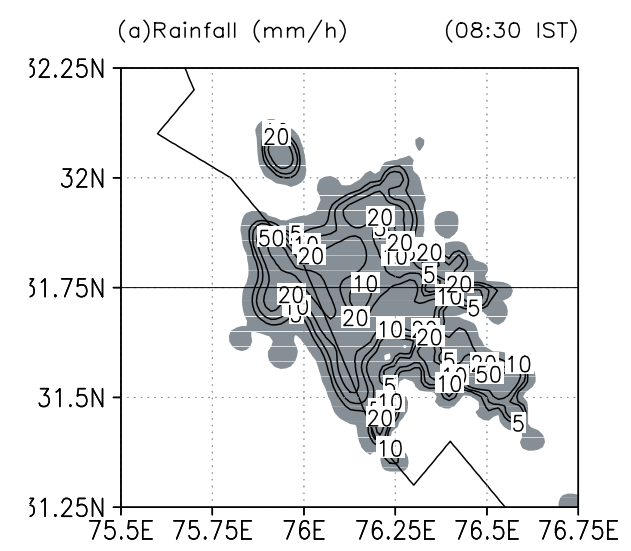

\section{$\operatorname{GSFC}(3 \mathrm{Km})$}
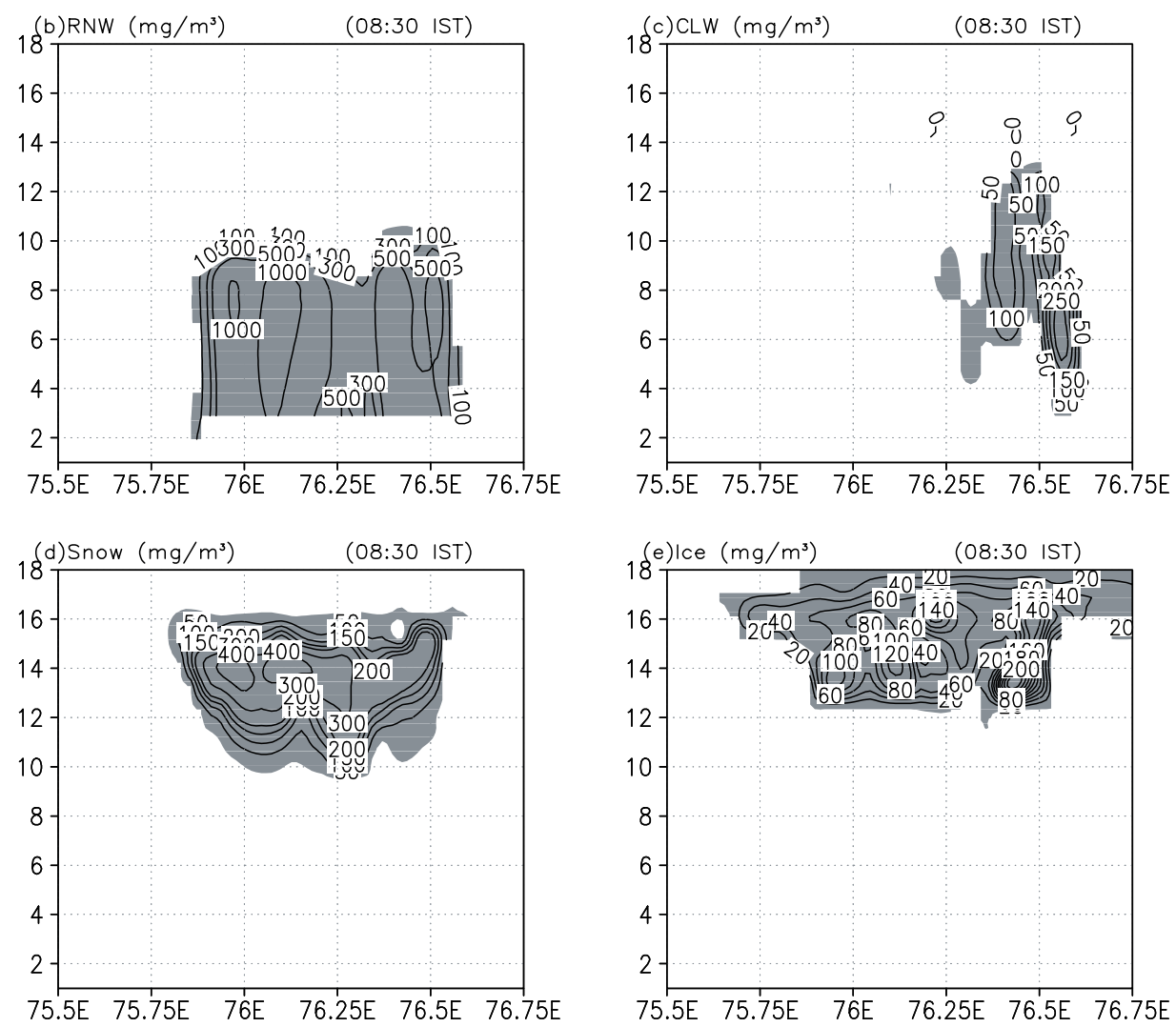

Figure 13. MM5-GSFC simulated location of (a) intense rainfall and vertical cross-section of hydrometeors, (b) RNW, (c) CLW, (d) snow and (e) ice on 15th July 2003 (08:30 IST).

shear in the meridional winds. (Schultz gives a similar message.) The relative humidity cross-section also indicates enhanced moisture supply due to southerlies. All these features are almost identical in the simulations applying the Schultz microphysical parameterization (figure 11). Schultz produces rainfall amounts as high as $100 \mathrm{~mm} / \mathrm{h}$ (figure 11a) just to the east of $76^{\circ} \mathrm{E}$. Cross-section of winds indicate a shear zone tilting with height featuring strong vertical shear.

At 08:30 IST (not shown) the rainfall patterns indicated southward and westward movement of the system. While the zonal wind showed no major change from the previous hour, the meridional wind showed further westward movement of the flow regimes (wind reversal and enhanced vertical shear). The humidity is high and there is a net westward movement of the system. In both GSFC and Schultz experiments at 08:30 IST, strong northerlies (downstream winds) dominated, with southward movement of the shear zone. GSFC indicates anvil formation as can be seen from the ascent overlying descent at $76.1^{\circ} \mathrm{E}$. In Schultz this feature is exaggerated as deep high-level cloud.

Similar analysis is carried out for another system moving in a southwesterly direction (not shown) over the southwestern part of Himachal Pradesh at 10:30 IST. Here, the rainfall maximum does 


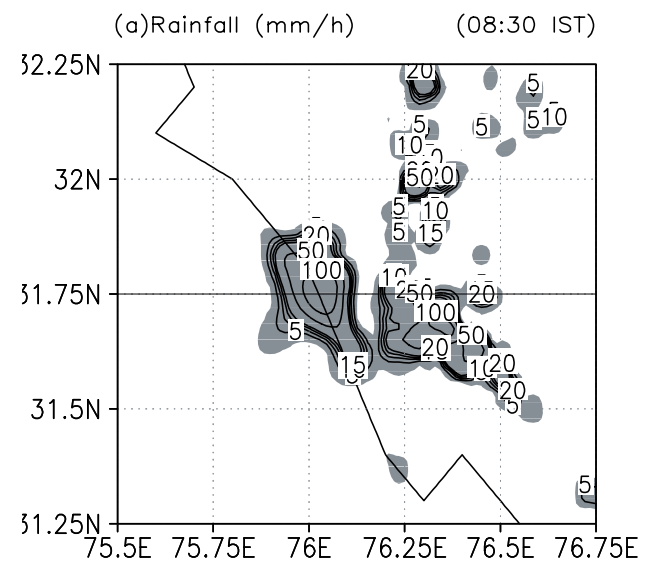

SCHULTZ $(3 \mathrm{Km})$
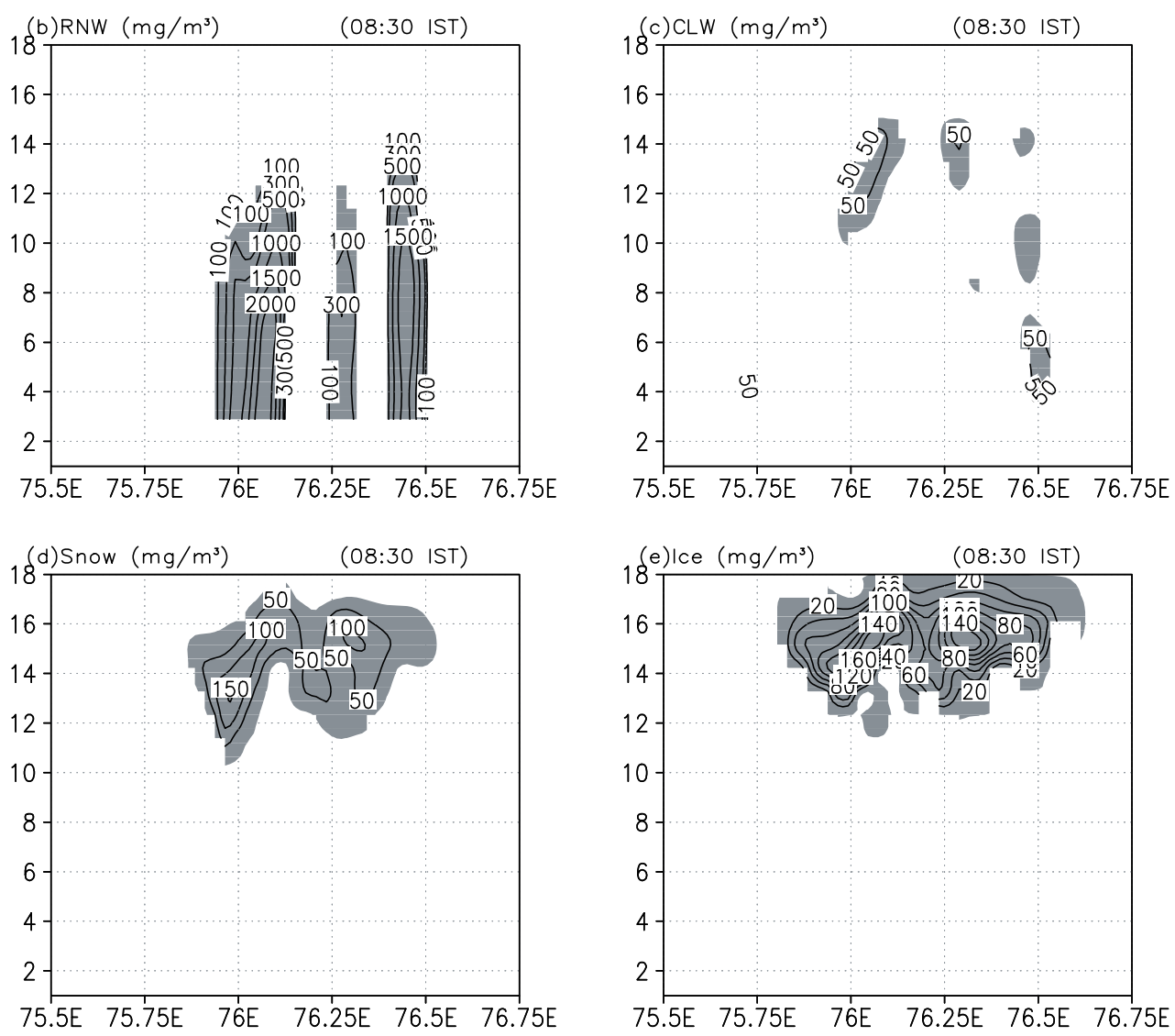

Figure 14. As in figure 15 but for the Schultz scheme.

not exceed $20 \mathrm{~mm} / \mathrm{hr}(50 \mathrm{~mm} / \mathrm{hr}$ in Schultz). The cross-section showed winds forming a tilted zone of strong shear and its movement towards the west with time. Furthermore, the relative humidity profile indicated a very high humidity anomaly travelling westwards. Schultz also produces similar circulation features, but the shear is weaker compared to the GSFC case. High-resolution observations are unavailable in this region of remote hilly terrain. In the following section, TMI-based observations of hydrometeor profiles are used to study the cloudburst event and a qualitative comparison is carried out against MM5 results.

\subsection{Hydrometeor structure}

The TMI algorithm (2A12) generates vertical profiles of hydrometeors from TMI brightness temperatures by blending the radiometric data with dynamical cloud models. For each pixel, the algorithm assigns a surface type (land/ocean/coast) and a freezing height and computes surface rain, convective surface rain, and profiles of hydrometeors (cloud liquid, cloud ice, water vapour, etc.) at 14 vertical levels at 5 -km horizontal resolution, along with latent heat and surface rain, over a $760 \mathrm{~km}$ swath. There is higher resolution 


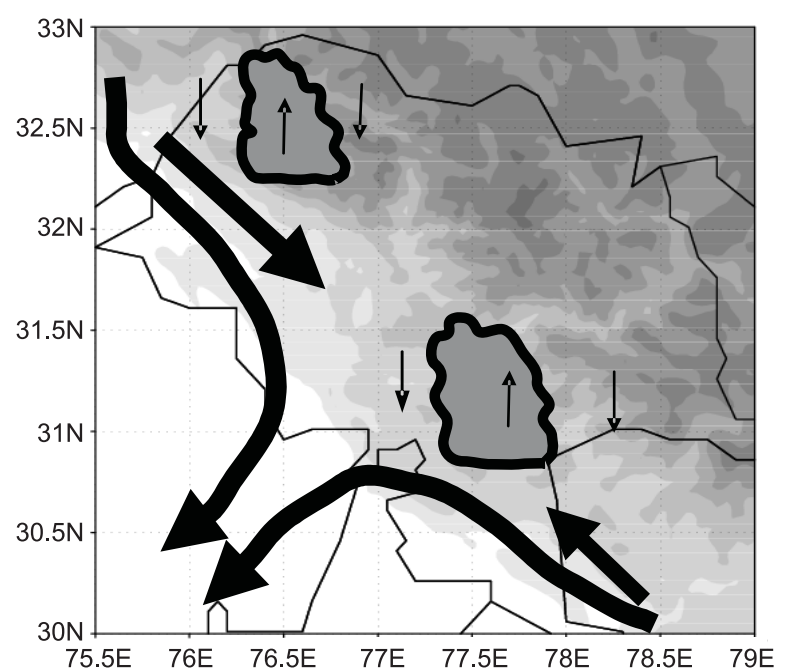

(a) Stage-1: 06:30 LT Separate Cells

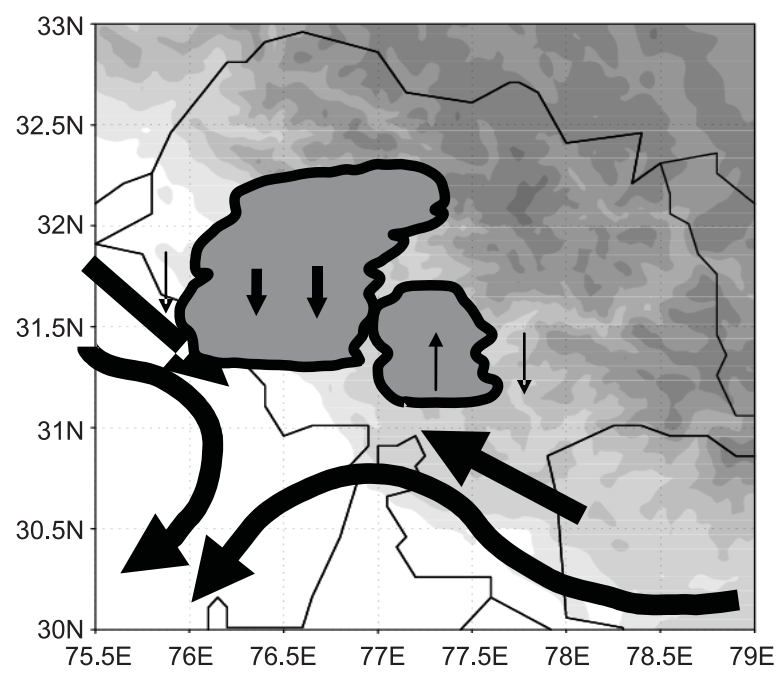

(b) Stage-2: 08:30 LT Merger cells and downpour

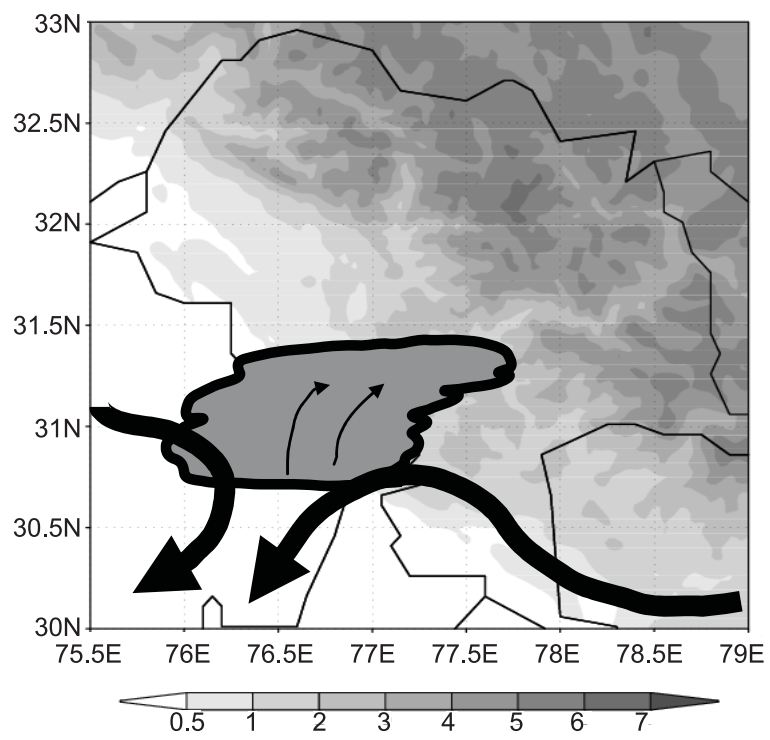

(c) Stage-3: 12:30 LT Dissipation

Figure 15. Conceptual model of a cloudburst (a) separate cells, (b) merger of cells and downpour and (c) dissipation. in the lower troposphere compared to the top of the atmosphere (surface to $4 \mathrm{~km}$ at $0.5 \mathrm{~km}$ resolution, 4-6 km at $1 \mathrm{~km}$ resolution, $6-10 \mathrm{~km}$ at $2 \mathrm{~km}$ resolution and $10-18 \mathrm{~km}$ at $4 \mathrm{~km}$ resolution). TMI products have previously been used to study monsoon depressions (Stano et al 2002) and gain insight into the hydrometeor profile of the Bay of Bengal cloud systems.

The observed data shown in figure 12 correspond to the satellite pass made at 00:27 IST, close to the cloudburst event. Figure 12(a) shows the instantaneous rainfall rate $(\mathrm{mm} / \mathrm{h})$ and the horizontal line indicates the axis of the vertical cross-section. The shading indicates the outline of the cloud. The measurements clearly indicate a deep cloud system, having a liquid-phase at lower altitudes and icephase at higher altitudes. Water content is mainly in the form of rain water and snow. Cloud liquidwater content is an order smaller, and ice content is two orders smaller.

Earlier studies by Das et al $(1998,1999)$ using a single-column model show the magnitude of cloud liquid water as marginally less than the magnitude of ice in tropical clouds. The TRMM product corresponding to another pass at 02:05 IST confirms a similar structure (not shown). The time of passage of the TRMM may not match with the observed time of maximum convection. Therefore, comparison between the TRMM observations with the model simulations has been carried out for the nearest time at which the observations and the simulations showed the maximum intensity of convection. The cross-section of the MM5 simulations is presented for box D (as indicated in figure 4) and the results are presented in figure 13 for the GSFC experiment. In agreement with observations, the GSFC experiment indicate large quantities of rainwater up to $8 \mathrm{~km}$ (figure 13b) compared to other hydrometeors. RNW (figure 13b) and CLW (figure 13c) magnitudes are higher than observed. While the magnitude of snow content (figure 13d) is in agreement with observations (figure 12d), it is confined to higher altitudes in the model. Note that MM5's vertical resolution above $10 \mathrm{~km}$ is higher than the TRMM analysis. The simulated ice (figure 13e) is an order higher compared to observations (figure 12e).

The experiment with the Schultz microphysical parameterization (figure 14) has slightly different characteristics. The rainfall amounts are higher compared to both observations and GSFC (figure 14a). Higher amounts of RNW (figure 14b) extending up to $14 \mathrm{~km}$ suggest that the Schultz scheme develops a deeper cloud system. Magnitude of CLW and snow (figure 14c and d, respectively) is strikingly less than both observations and GSFC, indicative of rapid falling precipitation below the 
freezing level. The magnitude of the ice (figure 14e) is the same as in GSFC.

Intercomparison of the two moisture schemes shows that the Schultz scheme produces higher amounts of rainfall due to rapid rainout of the CLW and snow compared to GSFC. The robustness of this conclusion was tested by examining the hydrometeor profiles at other model times as well as cross-sections taken at different rain locations (not shown). The overall higher magnitudes of the hydrometeors in the MM5 simulations compared to the TRMM observations is likely due to MM5's higher vertical resolution.

\subsection{Conceptual model}

The analysis from the two numerical experiments provides a conceptual model of the cloudburst based on the development of the vertical shear, vertical motion and the moisture distribution. The conceptual model of the cloudburst is shown in figure 15, which illustrates three stages in the lifecycle of the cloudburst. In the first stage, the two convective cells are separate and drift towards each other as part of the mean flow (figure 15a). Isolated heavy rain occurs during this stage. In the second stage (figure 15b), the two convective cells merge. Intensification follows due to strong wind shear and intense vertical motion. Heavy downpour and formation of the anvil also occurs. The storm moves rapidly southward due to strong steering flow. The third stage (figure 15c) is one of dissipation in which the two merged cells form one single large cell, which drifts westward and the cloudburst ceases.

\section{Conclusions}

The analysis of the numerically simulated cloudburst in the foothills of the Himalyas showed:

- the low-level convergence of southeasterlies and northwesterlies along the foothills coupled with vertical shear in wind and orographic uplifting leading to a short-lived, intensely precipitating convective storm (cloudburst) steered by the mean flow and travelling away from the foothills;

- a conceptual model of the cloudburst based on the development of the vertical shear, vertical motion and the moisture distribution in the simulated lifecycle of the cloudburst event;

- the cloud microphysical properties and vertical structure of hydrometeors in the cloudburst indicated by TRMM observations and simulations; and

- the updraft/downdraft structure and the rainsheet associated with the cloudburst.
Mesoscale simulations depend on global-model analysis for initial and lateral boundary conditions, which are likely to affect our results. Nevertheless, MM5 captures salient features as indicated by the analysis of the hydrometeor structure as observed by the TRMM satellite. At $30 \mathrm{~km}$ grid-resolution, MM5 generates a cloudburst event but it occurs too early. Experiments carried out at $9 \mathrm{~km}$ and $3 \mathrm{~km}$ grid-resolution improve the simulation of the cloudburst event and detail its structure.

Simulations indicate that low-level convergence of southeasterlies and northwesterlies along the foothills coupled with vertical shear in wind and orographic uplifting lead to intensely precipitating deep convection steered by the mean flow, travelling southwestwards away from the foothills. Analysis of the rainfall over the southwestern sector of the Himachal Pradesh region show that MM5 simulates the convective activity, shear and moisture buildup.

Comparison between the simulated vertical structure of hydrometeors and TRMM observations shows that MM5 overestimates the hydrometeor content. The overall higher magnitudes of the hydrometeors in the MM5 simulations compared to TRMM observations could be due to higher horizontal and vertical resolution of MM5. Intercomparison of two moisture schemes shows that the Schultz scheme produces higher amounts of rainfall due to rapid rainout of the cloud liquid water and snow compared to GSFC.

High-resolution measurements are essential for an accurate initial description of the system, its genesis, development and decay, and would obviously help to evaluate the simulation results. More extensive studies of cloudburst events are necessary to qauntify forecast skill and develop a real-time forecasting strategy.

The complex dynamical interaction among deep convection, orography and cloud-microphysics are only beginning to be quantified. More realistic numerical realization will improve basic knowledge and also increase the skill of cloudburst prediction. In spite of several limitations, we have shown that the prediction of cloudbursts by cloud-systemresolving mesoscale models is practicable. Forecasts would benefit from a dense network of surface measurements and Doppler radar in the western Himalayas.

\section{Acknowledgements}

Results reported in this paper are based on the collaborative work under an MOU signed between the National Center for Medium Range Weather Forecasting of the Department of Science \& Technology, Govt. of India and the National Center for 
Atmospheric Research, sponsored by the National Science Foundation, USA. Thanks are due to Bob Gall (NCAR), Jimy Dudhia (NCAR), Cindy Bruyere (NCAR) and the late S V Singh (NCMRWF). Simulations were carried out on NCMRWF and NCAR supercomputers.

\section{References}

Bougeault P, Binder P, Bizzi A, Dirks R, Houze R, Kuettner J, Smith R B, Steinacker R and Volkert H 2001 The MAP special observing period; Bull. Amer. Meteor. Soc. 82 433-462.

Chen S-H and Lin Y-L 2001 Orographic effects on a conditionally unstable flow over an idealized three-dimensional mesoscale mountain; MAP Newsletters 15 246-249.

Das S, Johnson D and Tao W-K 1999 Single-column and cloud ensemble model simulations of TOGA-COARE convective systems; J. Met. Soc. Japan 77 803-826.

Das S, Sud Y C and Surez M J 1998 Inclusion of a prognostic cloud scheme with the relaxed Arakawa-Schubert cumulus parameterization: Single-column model results; Q. J. R. Meteorol. Soc. 124 2671-2692.

Das S 2002 Evaluation and verification of MM5 forecasts over the Indian region; Proc. 12th PSU/NCAR Mesoscale Model Users Workshop, Boulder, CO, NCAR, 77-81.

Dudhia J 1996 A multi-layer soil temperature model for MM5; Preprints, The Sixth PSU/NCAR Mesoscale Model Users' Workshop, 22-24 July 1996, Boulder, Colorado, 49-50.

Grell G 1993 Prognostic evaluation of assumptions used by cumulus parameterizations; Mon. Weather Rev. 121 764-787.

Held G 1982 Comparison of radar observations of a devastating hailstorm and a cloudburst at Jan Smuts Airport; In: Cloud Dynamics; E M Agee and T Asai (eds) Advances in Earth and Planetary Sciences (Tokyo: Terra Scientific Publishing Company).

Hong S-Y and Pan H-L 1996 Nonlocal boundary layer vertical diffusion in a medium-range forecast model. Mon. Weather Rev. 124 2322-2339.
Houze R A 1993 Cloud Dynamics; International Geophysics Series. Vol. 53, Academic Press, Inc.

Kummerow, Christian, William Barnes, Toshiaki Kozu, James Shiue and Joanne Simpson 1998 The Tropical Rainfall Measuring Mission (TRMM) Sensor Package; J. Atmos. Oceanic Technol. 15 809-817.

Lin Y-L, Farley R D and Orville H D 1983 Bulk parameterization of snow field in a cloud model; J. Climate Appl. Meteor. 22 1065-1092.

Mann C F and Kuo Y-H 1998 Regional real time numerical weather prediction: Current status and future potential; Bull. Amer. Meteor. Soc. 79 253-263.

Orlanski I 1975 A rational subdivision of scales of atmospheric processes; Bull. Amer. Meteor. Soc. 56 527-530.

Paegle J, Pielke R, Dalu G, Miller W, Garratt J, Vukicevic T, Berri G and Nicolini M 1990: Predictability of flows over complex terrain; In: Atmospheric Processes over Complex Terrain, (ed.) W Bluman, Meteor. Monogr. 23 285-299.

Pielke R A 1984 Mesoscale meteorological modelling; San Diego, CA, Academic.

Rutledge S A and Hobbs P V 1984 The mesoscale and microscale structure and organizations of cloud and precipitation in midlatitude clouds. XII: A diagnostic modeling study of precipitation development in narrow cold-frontal rainbands; J. Atmos. Sci. 41 2949-2972.

Schultz P 1995 An explicit cloud physics parameterization for operational numerical weather prediction; Mon. Weather Rev. 123 3331-3343.

Smith R B 1979 The influence of mountains on the atmosphere; Adv. Geophys. 21 187-230.

Stano G, Krishnamurti T N, Vijay Kumar T S V and Arun Chakraborty 2002 Hydrometeor structure of a composite depression using the TRMM radar; Tellus $\mathbf{5 4}$ $370-381$

Tao W-K, Simpson J and McCumber M 1989 Ice-water saturation adjustment; Mon. Weather Rev. $\mathbf{1 1 7}$ 231-235.

Tao W-K, Sui C-H, Ferrier B, Lang S, Scala J, Chou M-D and Pickering K 1993 Heating, moisture and water budgets of tropical and midlatitude squall lines: comparisons and sensitivity to longwave radiation; J. Atmos. Sci. $\mathbf{5 0}$ 673-690. 